\title{
ESTIMATIVA DO ABATIMENTO DE EROSÃO APORTADO POR UM SISTEMA AGROSSILVIPASTORIL E SUA CONTRIBUIÇÃO ECONÔMICA ${ }^{1}$
}

\author{
Sabina Cerruto Ribeiro² ${ }^{2}$ Henrique Marinho Leite Chaves ${ }^{3}$, Laércio Antônio Gonçalves Jacovine ${ }^{4}$ e Márcio
} Lopes da Silva ${ }^{4}$

\begin{abstract}
RESUMO - A erosão do solo gera grandes prejuízos para o meio ambiente e para a sociedade, devido à perda de áreas agricultáveis e à conseqüente degradação dos recursos hídricos. Em vista desse panorama, a Agência Nacional de Águas desenvolveu o Programa do Produtor de Água. Com base na metodologia proposta por esse Programa, fez-se uma estimativa do potencial de abatimento de erosão para a atividade agrossilvipastoril na unidade agroflorestal da Companhia Mineira de Metais, em Paracatu -MG. Além disso, analisou-se a contribuição econômica das receitas geradas pela compensação monetária prevista no referido Programa, verificando que o sistema agrossilvipastoril permitiu um abatimento da erosão correspondente a 78,52\%. Esse serviço ambiental, por sua vez, poderia propiciar à empresa uma receita adicional de $\mathrm{R} \$ 100,00 \cdot \mathrm{ha}^{-1}$. ano ${ }^{-1}$. A análise da viabilidade econômica apontou um aumento de 27,7\% no VPL e VAE e de 7,0\% na TIR do sistema agrossilvipastoril, supondo-se a implementação do Programa do Produtor de Água na empresa.
\end{abstract}

Palavras-chave: Abatimento de erosão, programa do produtor de água, sistema agrossilvopastoril e viabilidade econômica.

\section{ESTIMATION OF EROSION REDUCTION CARRIED OUT BY AGROSILVOPASTURE SYSTEM AND ITS ECONOMIC CONTRIBUTION}

\begin{abstract}
Soil erosion causes extensive damage to society and environment through the loss of agricultural soils and the consequent degradation of water resources. Based on this context, the The Brazilian National Water Agency-ANA developed the "Water Provider Program". Erosion reduction was estimated for the agrosilvopasture activity in the agroforestry unit of "Companhia Mineira de Metais", in Paracatu, using the methodology of the "Programa do Produtor de Água". An analysis of the economic contribution of the revenue generated through the monetary compensation provided by the "Water Provider Program" was also performed. The results pointed to a $78.52 \%$ of erosion and sediment abatement. This environmental service would therefore provide the company for an additional income of $R \$ 100,00 . \mathrm{ha}^{-1}$. year $\mathrm{r}^{-1}$. The economic viability analysis pointed to an increase of $27.7 \%$ for NPV and EAV and of $7.0 \%$ for IRR of agrosilvopasture system, assuming the implementation of "Water Provider Program".
\end{abstract}

Keywords: Erosion reduction, "Water Provider Program”, agrosilvopasture system and Economic viability.

\footnotetext{
${ }^{1}$ Recebido em 18.09.2006 e aceito para publicação em 26.01.2007.

${ }^{2}$ Programa de Pós-Graduação em Ciência Florestal da UFV. E-mail: <sabina_ribeiro@ yahoo.com.br>.

${ }^{3}$ Departamento de Engenharia Florestal da Universidade de Brasília. E-mail: <hchaves@ tba.com.br>.

${ }^{4}$ Departamento de Engenharia Florestal da Universidade Federal de Viçosa. E-mail: <jacovine @ ufv.br>.
} 


\section{INTRODUÇÃO}

O uso inadequado dos solos pode causar, como efeitos mais perceptíveis sobre as águas superficiais, a sua impermeabilização e a erosão laminar (PRIMAVESI, 1997). A erosão acarreta grandes prejuízos para a sociedade, como perda de solos e à conseqüente degradação dos recursos hídricos, investimentos públicos em obras de infra-estrutura e a deterioração de áreas urbanas ou em urbanização. Além disso, a erosão do solo constitui a principal causa do empobrecimento precoce das terras produtivas (BERTONI L LOMBARDINETO, 1999). Por isso, é preciso incentivar o controle da erosão dentro das propriedades rurais e ao longo dos rios (JOHN, 2003).

O uso de políticas obrigatórias quase sempre não atinge seus objetivos; a aplicação de práticas mecânicas de forma isolada também não tem sido efetiva em razão, principalmente, do elevado custo para os agricultores. Porém, quando desenvolvidas com a participação e cooperação dos proprietários rurais, têm maiores possibilidades de êxito, desde que observados os seus interesses e que as práticas mecânicas sejam integradas a outras medidas de melhoria do sistema de produção (FRANCO et al., 2002).

Os proprietários rurais, em função da busca por um retorno econômico de curto prazo ou por falta de conhecimento técnico, acabam adotando um sistema de manejo que tende a exaurir o solo, causando, com isso, a degradação da qualidade da água dos mananciais. Assim, é necessário que sejam estabelecidas políticas públicas que revertam essa situação. Uma das alternativas que se vislumbra é dar algum incentivo ao produtor que venha a adotar um sistema de manejo de conservação do solo em sua propriedade.

Com base no princípio do incentivo no lugar da punição, a Agência Nacional de Águas (ANA) propôs o Programa do Produtor de Água, que visa à conservação de mananciais estratégicos, por meio da certificação e pagamento de uma compensação financeira a produtores rurais, relativos aos benefícios proporcionados pelo abatimento da erosão e sedimentação (ANA, 2004).

Entre os vários sistemas de manejo possíveis, o agrossilvopastoril, como o desenvolvido pela Companhia Mineira de Metais, em Paracatu, MG, destaca-se em relação à proteção dos mananciais e, com isso, apresenta um grande potencial de gerar compensação financeira aos proprietários rurais que o adotam. O sistema, segundo Vieira et al. (2003), permite a geração de diversos outros serviços ambientais importantes, além de aumentar a contribuição no que tange aos aspectos agronômicos, sociais e econômicos.

Considerando o exposto, este trabalho teve como objetivo calcular o valor do parâmetro de abatimento de erosão (Z), do modelo do Programa do Produtor de Água/ANA, para a atividade agrossilvopastoril, além de fazer uma análise financeira da contribuição econômica advinda do pagamento da compensação monetária, prevista no referido Programa.

\section{MATERIAL E MÉTODOS}

\subsection{Descrição da área de estudo}

O trabalho foi desenvolvido em agosto e dezembro de 2004, na Unidade Agroflorestal da Companhia Mineira de Metais (C.M.M.), no sistema agrossilvopastoril implantado em 1994, na fazenda Riacho, localizada no Município de Paracatu (17³6'09' S, 46 42' 02' W), englobando uma área total de 15.359 hectares, com $6.719,14$ hectares de área plantada. A precipitação anual da região varia entre 1.150 e $1.450 \mathrm{~mm}$, concentrada de novembro a março, o que gera um déficit hídrico anual médio de $171 \mathrm{~mm}$. As temperaturas médias máxima e mínima são de 32 e $16^{\circ} \mathrm{C}$, respectivamente. A formação vegetal é o Cerrado, com variações de campo limpo até matas (cerradão), nas manchas de solo mais férteis. O tipo de solo predominante é o Latossolo Vermelho Escuro distrófico, com textura argilosa. O relevo varia de plano a suave-ondulado.

Neste trabalho foram avaliados os clones 6,58 , 10,44 e 13, usados no sistema agrossilvopastoril implantado em 1994; os três primeiros são clones de Eucalyptus camaldulensis e os dois últimos, de Eucalyptus urophylla. Tais clones, selecionados em plantios comerciais da própria companhia, provenientes de sementes, são bem representativos do material genético plantado pela empresa.

O manejo aplicado ao sistema agrossilvopastoril da empresa possuía a seguinte cronologia: ano 0: eucalipto + arroz; ano 1: eucalipto + soja; ano 2: eucalipto + braquiária; e dos 3 aos 10 anos: eucalipto + gado.

$\mathrm{Na}$ área de estudo, a empresa usava o espaçamento de $10 \mathrm{~m} \mathrm{x} 4 \mathrm{~m}$ (250 indivíduos/hectare), com previsão de corte aos 10 anos, objetivando-se produzir toras para serraria. 


\subsection{Estimativa porcentual de abatimento de erosão do modelo do produtor de água para sistemas agrossilvopastoris}

As áreas correspondentes a cada cultura e ao eucalipto foram obtidas com base na projeção da copa do eucalipto no solo. No sistema agrossilvopastoril com clones de eucalipto aos 10 anos de idade, considerando que as copas eram homogêneas, foram feitas 40 medidas de projeção de copa no solo, em pontos distintos, tomadas quando o sol estava em sua posição zenital. As medidas de diâmetro foram tomadas em quatro pares de indivíduos diferentes, de cada um dos cinco clones avaliados, em um mesmo talhão, conforme Figura 1.

A seguir, transformaram-se os diâmetros em raio, obtendo as suas médias para o cálculo da área ocupada pelas copas dos indivíduos.

Considerando que no ano zero o diâmetro também foi igual a zero, fez-se um gráfico cujos pontos foram 0 e o diâmetro médio anteriormente obtido. A partir daí, calculou-se, tendo como base o gráfico, o diâmetro médio do eucalipto em diferentes idades.

Para a estimativa do sombreamento da copa no solo foi considerada uma área amostral de $200 \mathrm{~m}^{2}$, conforme a Figura 2.

Nos anos iniciais não houve sobreposição de copa. Então, a área de cada disco foi calculada a partir da fórmula da área de uma circunferência, segundo a equação:

$$
A=\pi \times r^{2}
$$

em que:

$$
\begin{aligned}
& \mathrm{A}=\text { área de cada disco }\left(\mathrm{m}^{2}\right) ; \\
& \mathrm{r}=\text { raio }(\mathrm{m}) ; \mathrm{e} \\
& \pi=\text { constante. }
\end{aligned}
$$

Após alguns anos da implantação, entretanto, as copas se tocaram (overlapping), conforme apresentado na Figura 2. Quando isso ocorreu, foi necessário, além de calcular a área dos discos, descontar as áreas de intersecções, calculadas por princípios trigonométricos.

As áreas das culturas foram calculadas pela subtração da área considerada, que é de $200 \mathrm{~m}^{2}$, pela área total obtida dos discos, segundo a equação:

$$
A_{\text {cultura }}=200-A_{\text {total }}
$$

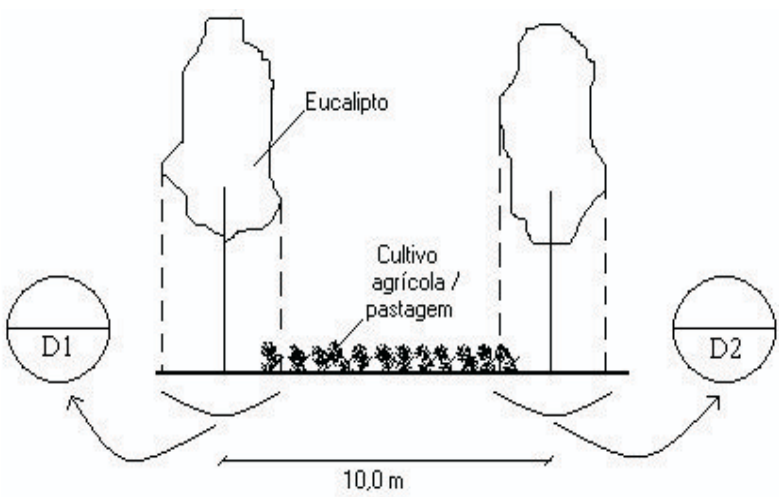

Figura 1 - Esquema das medições para determinar o diâmetro da área de projeção de copa do eucalipto.

Figure 1 -Measurement scheme to determine the average diameter of crown projection area of eucaliptus.

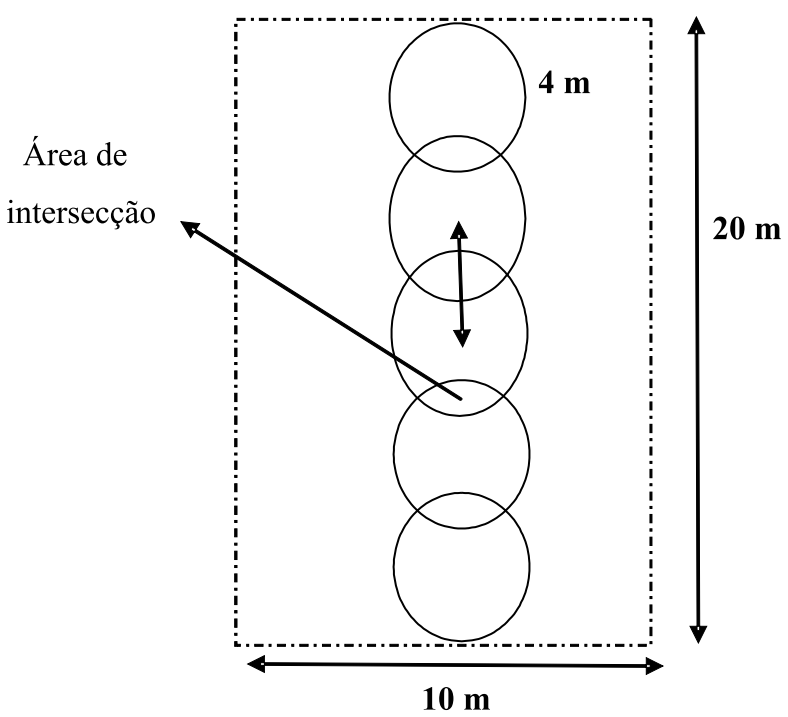

Figura 2 - Esquema representando a sobreposição de copas e a formação de áreas de intersecção.

Figure 2-Scheme representing the crowns overlapping and formation of intersection areas.

\subsubsection{O modelo do produtor de água (CHAVES et al., 2004)}

Com o objetivo de estimar os benefícios ambientais gerados a partir da adoção de práticas de manejo conservacionistas, usou-se uma metodologia baseada no abatimento da erosão na propriedade, a qual foi obtida pela simplificação da Equação Universal de Perda de Solo - USLE, dada por:

$$
\mathrm{A}=\text { R.K.L.S.C.P }
$$


onde,

$\mathrm{A}\left(\mathrm{t} \cdot \mathrm{ha}^{-1} \cdot \mathrm{ano}^{-1}\right)=$ perda de solo média anual da gleba de interesse;

$\mathrm{R}\left(\mathrm{MJ} \cdot \mathrm{mm} \cdot \mathrm{ha}^{-1} \cdot \mathrm{h}^{-1}\right)=$ erosividade da chuva e da enxurrada;

$\mathrm{K}\left(\right.$ ton $\left.\cdot h a \cdot h \cdot \mathrm{ha}^{-1} \cdot \mathrm{MJ}^{-1} \cdot \mathrm{mm}^{-1}\right)=$ erodibilidade do solo;

$\mathrm{L}($ adimensional $)=$ fator de comprimento de rampa;

$\mathrm{S}($ adimensional $)=$ fator de declividade da rampa;

$\mathrm{C}($ adimensional $)=$ fator de uso e manejo do solo; $\mathrm{e}$

$\mathrm{P}($ adimensional $)=$ fator de práticas conservacionistas.

Partindo-se de uma mesma área ou gleba de interesse, é possível considerar que vários dos parâmetros da USLE serão constantes antes e depois da implantação do projeto. Chamando de $\mathrm{Z}$ o produto $\mathrm{C} * \mathrm{P}$, após dividir a perda de solo sob a condição proposta $\left(A_{1}\right)$ pela perda sob a condição inicial $\left(\mathrm{A}_{0}\right)$ e cancelar os termos constantes na equação da USLE, obter-se-ia a equação seguinte:

$$
\mathrm{A}_{1} / \mathrm{A}_{0}=\mathrm{Z}_{1} / \mathrm{Z}_{0}
$$

A estimativa do abatimento da erosão e sedimentação é calculada pela equação 5 .

$$
\text { P.A.E. }(\%)=100\left(1-\mathrm{A}_{1} / \mathrm{A}_{0}\right)
$$

em que:

P.A.E.= percentual de abatimento de erosão e sedimentação;

$\mathrm{A}_{0}=$ estimativa da perda de solo antes da implantação do Programa (t.ha- ano $\left.^{-1}\right)$; e

$A_{1}=$ estimativa da perda de solo após a implantação do projeto conservacionista (t.ha- $\left.{ }^{-1} \cdot \mathrm{ano}^{-1}\right)$. que:

Substituindo a equação 4 na equação 5 , tem-se

$$
\text { P.A.E. }(\%)=100\left(1-Z_{1} / Z_{0}\right)
$$

em que:

$Z_{0}=$ valor do parâmetro $\mathrm{Z}$ antes da implantação do Programa; e

$Z_{1}=$ valor do parâmetro $Z$ após a implantação do projeto conservacionista.

O parâmetro Z do modelo do Produtor de Água foi estimado em duas situações: a) Antes da implantação do projeto e b) Após a implantação do projeto agrossilvopastoril.

No primeiro caso, ou seja, antes da implantação do projeto, considerou-se uma situação de pastagem degradada (linha de base), que era a condição presente na região antes da implantação do sistema agrossilvopastoril. A estimativa do valor $\mathrm{Z}$ após a implantação do projeto agrossilvopastoril foi baseada num ciclo de corte de 10 anos. A equação a seguir foi usada para estimar o fator $Z$ em cada combinação de cultura e eucalipto (adaptado de CHAVES et al., 2004):

$$
Z_{x / e}=\frac{Z_{x} \times A_{x}+Z_{e} \times A_{e}}{A_{\text {Total }}}
$$

em que:

$Z_{\mathrm{x} / \mathrm{e}}=$ valor do parâmetro $Z$ da cultura $x$ e o eucalipto;

$\mathrm{Z}_{\mathrm{x}}=$ valor do parâmetro $\mathrm{Z}$ para a cultura $\mathrm{x}$;

$\mathrm{A}_{\mathrm{x}}=$ área ocupada pela cultura $\mathrm{x}$;

$\mathrm{Z}_{\mathrm{e}}=$ valor do parâmetro $\mathrm{Z}$ para o eucalipto;

$\mathrm{A}_{\mathrm{e}}=$ área ocupada pelo eucalipto; $\mathrm{e}$

$\mathrm{A}_{\text {Total }}=$ área ocupada pela cultura x e o eucalipto.

Os valores individuais do parâmetro $Z$ para as culturas e para o eucalipto são apresentados no Quadro 1 .

Uma média de todas as combinações foi feita, a fim de se obter um valor médio para o parâmetro $\mathrm{Z}$, conforme a equação (adaptado de CHAVES et al., 2004):

$$
Z_{\text {Médio }}=\frac{Z_{a / e}+Z_{s / e}+Z_{p / e}+\sum_{i=3}^{10} Z_{g / e i}}{10}
$$

em que:

$\mathrm{Z}_{\text {Médio }}=$ média do parâmetro $\mathrm{Z}$ no sistema agrossilvopastoril;

$\mathrm{Z}_{\mathrm{a} / \mathrm{e}}=$ valor do parâmetro $\mathrm{Z}$ para o consórcio do arroz e o eucalipto;

$Z_{\text {s/e }}=$ valor do parâmetro $Z$ para o consórcio da soja e o eucalipto;

$\mathrm{Z}_{\mathrm{p} / \mathrm{e}}=$ valor do parâmetro $\mathrm{Z}$ para o consórcio da pastagem e o eucalipto; e

$Z_{\mathrm{g} / \mathrm{ei}}=$ valor do parâmetro $\mathrm{Z}$ para o consórcio de gado com o eucalipto no ano $\mathrm{i}$. 
Quadro 1 - Valores de Z para diferentes usos e manejos convencionais e conservacionistas Table 1-Z parameter values for conventional and conservationist managements

\begin{tabular}{|c|c|c|c|}
\hline Manejo convencional & $\mathrm{Z}_{0}$ & Manejo Conservacionista & $\mathrm{Z}_{1}$ \\
\hline \multirow[t]{8}{*}{$\overline{\text { Grãos }}$} & 0,25 & Grãos, rotação & 0,20 \\
\hline & & Grãos, em nível & 0,13 \\
\hline & & Grãos, rotação, em nível & 0,10 \\
\hline & & Grãos, faixas vegetadas & 0,08 \\
\hline & & Grãos, cordões vegetação & 0,05 \\
\hline & & Grãos, terraços & 0,05 \\
\hline & & Grãos, rotação, terraços & 0,02 \\
\hline & & Grãos, plantio direto & 0,03 \\
\hline \multirow[t]{3}{*}{ Algodão/Mandioca } & 0,62 & Algodão/Mandioca, rotação & 0,40 \\
\hline & & Algodão/Mandioca, em nível & 0,31 \\
\hline & & Algodão/Mandioca, plantio direto & 0,04 \\
\hline \multirow[t]{3}{*}{$\overline{\text { Cana-de-açúcar }}$} & 0,10 & Cana-de-açúcar, em nível & 0,05 \\
\hline & & Cana-de-açúcar, em faixas & 0,03 \\
\hline & & Cana-de-açúcar, terraços & 0,01 \\
\hline \multirow[t]{3}{*}{$\overline{\text { Batata }}$} & 0,75 & Batata, em nível & 0,38 \\
\hline & & Batata, em faixas & 0,22 \\
\hline & & Batata, terraços & 0,08 \\
\hline \multirow[t]{2}{*}{$\overline{\text { Café }}$} & 0,37 & Café, em nível & 0,19 \\
\hline & & Café, em faixas & 0,11 \\
\hline Hortaliças & 0,50 & Hortaliças, em nível & 0,25 \\
\hline \multirow[t]{3}{*}{ Pastagem degradada } & 0,25 & Pastagem recuperada & 0,12 \\
\hline & & Pastagem recuperada + terraços & 0,04 \\
\hline & & Pastagem, rotação com grãos & 0,10 \\
\hline Capoeira degradada & 0,15 & Reflorestamento denso & 0,01 \\
\hline Cascalheira / solo nu & 1,00 & Reflorestamento ralo & 0,03 \\
\hline
\end{tabular}

Fonte: Chaves et al., 2003.

O valor médio do parâmetro $\mathrm{Z}$ foi dessa forma, considerado como o correspondente para o sistema agrossilvopastoril utilizado pela empresa.

O porcentual de abatimento de erosão e sedimentação (PAE), obtido com a implantação do projeto, foi dado pela equação (adaptado de CHAVES et al., 2004):

$$
\text { P.A.E. }(\%)=100\left(1-\frac{Z_{\text {Médio }}}{Z_{0}}\right)
$$

A partir do valor obtido, determinaram-se os valores de pagamento incentivado (VPI) em função do abatimento de erosão proporcionado (PAE), de acordo com Quadro 2.

Quadro 2 - Valores sugeridos para pagamentos incentivados (VPI), em função do abatimento de erosão proporcionado (PAE)

Table 2 - Suggested values for incentive payments, depending on erosion abatement

\begin{tabular}{lccc}
\hline PAE $(\%)$ & $25-50 \%$ & $51-75 \%$ & $75-100 \%$ \\
\hline VPI & 50 & 75 & 100 \\
$(\mathrm{R} \$ /$ ha $)$ & & & \\
\hline
\end{tabular}

Fonte: Chaves et al., 2003.
Para determinar o valor por ano, dividiu-se a estimativa do talhão por 10 , que corresponde ao número de anos de implantação do sistema agrossilvopastoril considerado.

\subsection{Avaliação financeira}

\subsubsection{Fluxo de caixa}

Uma avaliação dos custos e receitas obtidos com o sistema agrossilvopastoril foi feita, a fim de se comparála com as possíveis adicionalidades a serem obtidas com a implantação do Programa do Produtor de Água. Para isso, foram usados dados fornecidos pela C.M.M.

\subsubsection{Critérios de avaliação}

Os critérios usados para se verificar a viabilidade financeira do sistema agrossilvopastoril, antes e depois da implantação do Programa do Produtor de Água, são apresentados a seguir.

a) Valor Presente Líquido (VPL) Representa a diferença entre receitas e custos, atualizada de acordo com determinada taxa de desconto.

R. Árvore, Viçosa-MG, v.31, n.2, p.285-293, 2007 


$$
V P L=\sum_{j=0}^{n} R j(1+i)^{-j}-\sum_{j=0}^{n} C j(1+i)^{-j}
$$
em que:

$\mathrm{C}_{\mathrm{j}}=$ custo no final do período $\mathrm{j}$ considerado;

$\mathrm{R}_{\mathrm{j}}=$ receita no final do período $\mathrm{j}$ considerado;

$\mathrm{i}=$ taxa de desconto; e

$\mathrm{n}=$ duração do projeto, em número de períodos.

O projeto será economicamente viável quando VPL for maior do que zero.

b) Taxa Interna de Retorno (TIR) É a taxa de desconto que iguala o valor atual das receitas (futuras) ao valor atual dos custos (futuros) do projeto.

$$
\sum_{j=0}^{n} R j(1+T I R)^{-j}=\sum_{j=0}^{n} C j(1+T I R)^{-j}
$$

em que:

$\mathrm{C}_{\mathrm{j}}=$ custo no final do período $\mathrm{j}$ considerado;

$\mathrm{R}_{\mathrm{j}}=$ receita no final do período $\mathrm{j}$ considerado;

TIR = taxa Interna de Retorno; e

$\mathrm{n}=$ duração do projeto, em número de períodos.

Um projeto será viável economicamente se sua TIR for maior do que a taxa mínima de atratividade do capital, que no presente trabalho é igual a $10 \%$.

c) Valor Anual Equivalente (VAE) Transforma o valor presente líquido em um fluxo anual e constante de receitas/custos, de duração igual à de horizonte do projeto.

em que:

$$
V A E=\frac{V P L * i}{\left[1-(1+i)^{-n}\right]}
$$

VPL = Valor Presente Líquido;

$\mathrm{i}=$ taxa de desconto; $\mathrm{e}$

$\mathrm{n}=$ duração do projeto, em número de períodos.

O projeto será considerado economicamente viável quando VAE for maior que zero, indicando que os benefícios periódicos são maiores do que os custos periódicos.

\subsubsection{Taxa de desconto}

No setor florestal há muita controvérsia no que tange à escolha da taxa de desconto a ser usada, sendo observadas variações que vão desde $4 \%$ até $15 \%$ a.a. (LIMA JÚNIOR, 1995). Nesta avaliação financeira foi aplicada a taxa de desconto de $10 \%$ a.a., que é a mais recomendada, conforme afirmaram Oliveira e Vosti (1997) e Sá et al. (2000) apud
Bentes-Gama et al. (2005) e Lima Júnior (1995). Esse valor escolhido também condiz com as recomendações do Centro de Estudos Integrados sobre o Meio Ambiente e Mudanças Climáticas do Ministério do Meio Ambiente em um documento que trata da Proposta Revisada de Critérios e Indicadores de Elegibilidade para a Avaliação de Projetos Candidatos ao Mecanismo de Desenvolvimento Limpo (MDL) no Brasil (BRASIL, 2002).

\section{RESULTADOS E DISCUSSÃO}

\subsection{Estimativa do parâmetro $Z$}

O parâmetro $Z$ foi determinado para todas as formas de manejo $\left(Z_{\mathrm{a} / \mathrm{e}}, \mathrm{Z}_{\mathrm{s} / \mathrm{e}}, \mathrm{Z}_{\mathrm{p} / \mathrm{e}} \mathrm{e} \mathrm{Z}_{\mathrm{g} / \mathrm{i}}\right)$ nos 10 anos de implantação do projeto, cujos resultados são apresentados no Quadro 3. Tomando como base esses resultados, obteve-se um valor médio do parâmetro $\mathrm{Z}$, para o sistema agrossilvopastoril, igual a 0,0537.

O porcentual de abatimento de erosão e sedimentação (PAE) foi calculado para uma pastagem degradada e para o sistema agrossilvopastoril utilizando a equação 5. Na condição antes da implantação do projeto (linha de base), o PAE foi igual a zero e no caso do sistema agrossilvopastoril, de 78,52\%, comprovando melhoria considerável na diminuição da erosão.

Considerando os dados apresentados no Quadro 2 e que o PAE para o sistema agrossilvopastoril foi igual a $78,52 \%$, ter-se-ia um valor correspondente para o VPI de $\mathrm{R} \$ 100,00$. hectare $^{-1} \mathrm{ano}^{-1}$. É importante destacar que, neste trabalho, considerou-se que o valor a ser recebido pela Companhia, proveniente do VPI, ocorreria no décimo ano com um montante final de $\mathrm{R} \$ 1.000,00$ por rotação. Este valor está condizente com o que certos produtores rurais estão dispostos a receber como compensação para recuperar áreas degradadas, conforme estudo de Veiga e Denardin (2001) nabacia dorio Macabu, noNorte fluminense, onde proprietários de gado leiteiro, após uma entrevista, com base na metodologia de valoração de contingente proposta por Pearce e Turner (1990), revelaram que estariam dispostos a receber $\mathrm{R} \$ 50,00$, no caso de proprietários de áreas de encosta, e R $\$ 250,00$ no caso de proprietários de terras ao longo de rios e córregos, a fim de que áreas de pasto fossem usadas para reflorestamento.

O Programa Conservador das Águas, implantado pela prefeitura da cidade de Extrema, MG, em parceria com a The Nature Conservancy (TNC) é outro exemplo de pagamento por serviços ambientais que relacionam as florestas à quantidade e qualidade de água. Segundo esse Programa, que é a primeira iniciativa municipal brasileira desse gênero, os produtores rurais que adotaram práticas 
conservacionistas que efetivamente promoveram o abatimento da erosão e sedimentação na sub-bacia hidrográfica das Posses irão receber $\mathrm{R} \$ 37,00 /$ ha. Isso

Quadro 3 - Estimativa do parâmetro Z do Programa do Produtor de Água/ANA

Table 3-Z parameter estimative for the ANA's “Water Provider Program"

\begin{tabular}{lcc}
\hline \multicolumn{1}{c}{ Tratamento } & Ano & Parâmetro Z \\
\hline Eucalipto + arroz & 0 & $\mathrm{Z}_{\mathrm{a} / \mathrm{e}}=0$ \\
Eucalipto + soja & 1 & $\mathrm{Z}_{\mathrm{s} / \mathrm{e}}=0,0316$ \\
Eucalipto + pasto & 2 & $\mathrm{Z}_{\mathrm{p} / \mathrm{e}}=0,0327$ \\
Eucalipto + gado & 3 & $\mathrm{Z}_{\mathrm{g} / \mathrm{e} 3}=0,0360$ \\
& 4 & $\mathrm{Z}_{\mathrm{g} / \mathrm{e} 4}=0,0407$ \\
& 5 & $\mathrm{Z}_{\mathrm{g} / \mathrm{e} 5}=0,0470$ \\
& 6 & $\mathrm{Z}_{\mathrm{g} / \mathrm{e} 6}=0,0541$ \\
& 8 & $\mathrm{Z}_{\mathrm{g} / \mathrm{e} 7}=0,0615$ \\
& 9 & $\mathrm{Z}_{\mathrm{g} / \mathrm{e} 8}=0,0692$ \\
& 10 & $\mathrm{Z}_{\mathrm{g} / \mathrm{e} 9}=0,0778$ \\
\hline Média ponderada do ciclo agroflorestal & 0,0868 \\
\hline
\end{tabular}

representa um incentivo econômico para proprietários que ainda têm áreas de floresta nativa e, ou, que desejem se adequar ao código florestal vigente (TNC, 2006).

Outra forma de incentivo à melhoria da qualidade $\mathrm{e}$ quantidade daáguaé o mecanismo diferenciado de pagamento pelo uso da água que foi adotado na Bacia do Rio Paraíba do Sul. Segundo esse mecanismo, incentivos financeiros serão concedidos aos usuários que fizerem investimentos, com recursos próprios, em ações que resultem em efetivos benefícios à disponibilidade de água na bacia. Dessa forma, será possível abater em até $50 \%$ o valor referente ao consumo e captação de água e, ao mesmo tempo, garantir melhoria da qualidade e quantidade da água na bacia (CEIVAP, 2006).

\subsection{Avaliação financeira}

\subsubsection{Fluxo de caixa}

O fluxo de caixa obtido a partir de dados fornecidos pela C.M.M. está representado no Quadro 4.

Quadro 4 - Fluxo de caixa do sistema agrossilvipastoril com rotação de 10 anos Table 4-Cash flow for agrosilvipasture system with a 10-year rotation

\begin{tabular}{|c|c|c|c|c|c|}
\hline \multirow[t]{2}{*}{ Ano } & \multicolumn{2}{|c|}{ Receitas } & \multicolumn{2}{|c|}{ Custos } & \multirow{2}{*}{$\begin{array}{l}\text { Saldo } \\
\mathrm{R} \$ / \mathrm{ha}\end{array}$} \\
\hline & Fonte de receita & $\mathrm{R} \$ / \mathrm{ha}$ & Fonte de custo & $\mathrm{R} \$ / \mathrm{ha}$ & \\
\hline$\overline{0}$ & Venda de arroz & 846,72 & $\begin{array}{l}\text { Implantação de eucalipto } \\
\text { Cultivo de arroz } \\
\text { Desp. Administrativa }\end{array}$ & $\begin{array}{c}2.046,78 \\
690,40 \\
99,24\end{array}$ & $-1.989,69$ \\
\hline 1 & Venda de soja & 907,20 & $\begin{array}{l}\text { Cultivo de soja } \\
\text { Manutenção do eucalipto } \\
\text { Desp. Administrativa }\end{array}$ & $\begin{array}{c}856,91 \\
299,24 \\
99,24\end{array}$ & $-348,19$ \\
\hline 2 & - & - & $\begin{array}{l}\text { Manutenção do eucalipto } \\
\text { Formação de pastagem } \\
\text { Desp. Administrativa }\end{array}$ & $\begin{array}{c}263,81 \\
323,42 \\
99,24\end{array}$ & $-686,47$ \\
\hline 3 & Arrobas (@) de Carne & 858,00 & $\begin{array}{l}\text { Manutenção do eucalipto } \\
\text { Pecuária } \\
\text { Desp. Administrativa }\end{array}$ & $\begin{array}{l}237,08 \\
775,28 \\
99,24\end{array}$ & $-253,59$ \\
\hline 4 & Arrobas (@) de Carne & 858,00 & $\begin{array}{l}\text { Manutenção do eucalipto } \\
\text { Pecuária } \\
\text { Desp. Administrativa }\end{array}$ & $\begin{array}{c}144,17 \\
603,97 \\
99,24\end{array}$ & 10,62 \\
\hline 5 & Arrobas (@) de Carne & 858,00 & $\begin{array}{l}\text { Manutenção do eucalipto } \\
\text { Pecuária } \\
\text { Desp. Administrativa }\end{array}$ & $\begin{array}{c}144,17 \\
603,97 \\
99,24\end{array}$ & 10,62 \\
\hline 6 & Arrobas (@) de Carne & 858,00 & $\begin{array}{l}\text { Manutenção do eucalipto } \\
\text { Pecuária } \\
\text { Desp. Administrativa }\end{array}$ & $\begin{array}{c}144,17 \\
603,97 \\
99,24\end{array}$ & 10,62 \\
\hline 7 & Arrobas (@) de Carne & 858,00 & $\begin{array}{l}\text { Manutenção do eucalipto } \\
\text { Pecuária } \\
\text { Desp. Administrativa }\end{array}$ & $\begin{array}{c}144,17 \\
603,97 \\
99,24\end{array}$ & 10,62 \\
\hline 8 & Arrobas (@) de Carne & 858,00 & $\begin{array}{l}\text { Manutenção do eucalipto } \\
\text { Pecuária } \\
\text { Desp. Administrativa }\end{array}$ & $\begin{array}{c}144,17 \\
603,97 \\
99,24\end{array}$ & 10,62 \\
\hline 9 & Arrobas (@) de Carne & 858,00 & $\begin{array}{l}\text { Manutenção do eucalipto } \\
\text { Pecuária } \\
\text { Desp. Administrativa }\end{array}$ & $\begin{array}{c}144,17 \\
603,97 \\
99,24\end{array}$ & 10,62 \\
\hline 10 & $\begin{array}{l}\text { Arrobas (@) de Carne } \\
\text { Receita c/ madeira }\end{array}$ & $\begin{array}{c}858,00 \\
11.500,00\end{array}$ & $\begin{array}{l}\text { Manutenção do eucalipto } \\
\text { Pecuária } \\
\text { Desp. Administrativa }\end{array}$ & $\begin{array}{c}188,31 \\
603,97 \\
99,24\end{array}$ & $11.466,49$ \\
\hline
\end{tabular}

Fonte: Adaptado de dados fornecidos pela empresa. 
Os custos envolvidos com a implantação do arroz e dasojasãode $\mathrm{R} \$ 690,40 \mathrm{e}$ \$856,91 porhectare, respectivamente. Essas duas culturas não apresentam lucratividade significativa, pois a receita alcançada com elas é pouco maior do que o seu custo. Entretanto, o ganho com essas culturas advém da melhoria física e, principalmente, química do solo, o que proporciona melhor produtividade da pastagem e da madeira. O gado apresenta produtividade média de 8,25 arrobas.ha${ }^{1}$. ano $^{-1}$. Além disso, mais 8,25 arrobas são compradas. Considerando um preço de venda de $\mathrm{R} \$ 52,00 /$ arroba, obtémse uma receita de $\mathrm{R} \$ 858,00 . \mathrm{ha}^{-1} \mathrm{ano}^{-1}$. É importante ressaltar que nos custos da pecuária, apresentados no Quadro 3, estão embutidas despesas cominsumos, mão-de-obra, aquisição de novilhos e depreciação. Oeucalipto tem custode implantação de $\mathrm{R} \$ 2.046,78 / \mathrm{ha}$. Do primeiro ao décimo ano subseqüente, existem os custos de manutenção que totalizam $\mathrm{R} \$ 1.853,48$ / ha. Sua produtividade é de 40 st.ha $^{-1}$ ano $^{-1}$, proporcionando 400 st/ha à idade de 10 anos. O preço de mercado considerado para venda foi de $\mathrm{R} \$ 28,75 / \mathrm{st}$, ou seja, se o corte for feito aos 10 anos, obter-se-á uma receita de $\mathrm{R} \$ 11.500,00 /$ ha.

\subsubsection{Critérios de avaliação}

OVPL, a TIR e o VAE, que foram os critérios econômicos usados para avaliar a viabilidade financeira do sistema agrossilvopastoril, estão apresentados no Quadro 5.

Os resultados indicarammque o sistemaagrossilvopastoril é um projeto economicamente viável, sem considerar o VPI, apresentando VPL, VAE e TIR de R \$1.391,51, R \$138,77 e $14,51 \%$, respectivamente. Considerando o recebimento do valor de pagamento incentivado(VPI), proveniente doPrograma doProdutor de Água, constatou-se que a viabilidade financeira do projeto analisado pelos critérios VPL, VAE e TIR foi incrementada, obtendo-se R $\$ 1.777,05, \mathrm{R} \$ 177,32$ e 15,53\%, respectivamente. Esse incremento foi de $27,7 \%$ para o VPL e VAE e de 7,0\% para a TIR, representando atrativo adicional paraaimplantaçãodesse Programa nosistemaagrossilvopastoril.

Quadro 5 - VPL, TIR e VAE do sistema agrossilvopastoril da CMM, antes e depois da implementação do Programa do Produtor de Água, a uma taxa de desconto de $10 \%$ a.a.

Table 5-NPV, IRR and EAV for C.M.M's agrossilvopasture system, after and before implementation of "Water Provider Program", with a discount rate of $10 \%$ peryear

\begin{tabular}{lccc}
\hline Cenário & $\begin{array}{c}\text { VPL } \\
(\mathrm{R} \$ / \mathrm{ha})\end{array}$ & $\begin{array}{c}\text { TIR } \\
(\% \text { a.a. })\end{array}$ & $\begin{array}{c}\text { VAE } \\
\left(\mathrm{R} \$ \cdot \mathrm{ha}^{-1} \cdot \mathrm{ano}^{-1}\right)\end{array}$ \\
\hline Sem VPI & $\mathrm{R} \$ 1.391,51$ & $14,51 \%$ & 138,77 \\
Com VPI & $\mathrm{R} \$ 1.777,05$ & $15,53 \%$ & 177,32 \\
\hline
\end{tabular}

R. Árvore, Viçosa-MG, v.31, n.2, p.285-293, 2007

\section{CONCLUSÕES}

- O sistema agrossilvopastoril permitiu um abatimento da erosão, em comparação com uma pastagem degradada.

- Com a implantação do Programa do Produtor de Água, o sistema agrossilvopastoril permitiria o recebimento de uma receita extra considerável, contribuindo para o aumento da viabilidade econômica da atividade.

- De forma geral, os critérios de avaliação econômica utilizados (VPL, TIR e VAE) apontaram para um aumento da viabilidade financeira do sistema agrossilvopastoril, supondo-se uma possível implantação do Programa do Produtor de Água na empresa.

- A implementação do Programa do Produtor de Água, proposto pela ANA, é um instrumento de grande importância como forma de incentivo ao produtor, para a efetivação de práticas de manejo conservacionistas do solo e, assim, promover melhorias da qualidade da água das bacias hidrográficas.

\section{REFERÊNCIAS}

AGÊNCIA NACIONAL DE ÁGUAS - ANA. Manual Operativo do Programa "Produtor de Água”. In: CHAVES, H. M.et al. Quantificação dos benefícios e compensações do "Programa do Produtor de água” (ANA): I Teoria. Revista Brasileira de Recursos Hídricos, v.9, n.3, p.5-14, 2004.

BENTES-GAMA, M. M. et al. Análise econômica de sistemas agroflorestais na Amazônia Ocidental, Machadinho d'Oeste - RO. Revista Árvore, v.29, n.3, p.401-411, 2005.

BERTONI, J.; LOMBARDI NETO, F. Conservação do solo. São Paulo: Ícone, 1999. 355p.

BRASIL. Ministério da Agricultura.

Proposta revisada de critérios e indicadores de elegibilidade para avaliação de projetos candidatos ao Mecanismo de Desenvolvimento Limpo (MDL). Disponível em: <http:// www.centroclima.org.br/ccpdf/criterio.pdf $>$. Acesso em: 16 de janeiro de 2007. 
CEIVAP. DELIBERAÇÃO CEIVAP No 70/2006. Disponível em: <http:// www.ceivap.org.br>. Acesso em: 23 de janeiro de 2007.

CHAVES, H. M. et al. Quantificação dos benefícios e compensações do "Programa do Produtor de água" (ANA): I Teoria. Revista Brasileira de Recursos Hídricos, v.9, n.3, p.5-14, 2004.

FRANCO, F. S. et al. Quantificação de erosão em sistemas agroflorestais e convencionais na Zona da Mata de Minas Gerais. Revista Árvore, v.26, n.6, p.751-760, 2002.

JOHN, L. São Paulo inova no controle à erosão. Disponível em: < http://www.saopaulo. sp.gov.br/sis/leimprensa.php?id=31501>. Acesso em: 13 abr. 2004.

LIMA JÚNIOR, V.B. Determinação da taxa de desconto para uso na avaliação de projetos de investimentos florestais. 1995. 90p. Dissertação (Mestrado em Ciência Florestal) - Universidade Federal de Viçosa, Viçosa, MG, 1995.
PEARCE, D.W.; TURNER, R.K. Economics of natural resources and the

environment. Baltimore, The Johns Hopkins University Press, 1990. 378p.

PRIMAVESI, A. Agroecologia: ecosfera, tecnosfera e agricultura. São Paulo: Nobel, 1997. 200p.

TNC. TNC fecha convênio com prefeitura do município de Extrema para conservação de bacia hidrográfica. Disponível em: <http://www.nature.org/>. Acesso em 23 de janeiro de 2007.

VEIGA NETO, F.; DENARDIN, V. F. Compensação por serviços ambientais de florestas: o caso de Conceição de Macabú - RJ. In: ENCONTRO NACIONAL DA SOCIEDADE BRASILEIRA DE ECONOMIA ECOLÓGICA, 4., 2001, Belém.

Anais... Belém: 2001. CD-ROM.

VIEIRA, A. R. R.; FEISTAUER, D.; SILVA, V. P. Adaptação de espécies arbóreas nativas em um sistema agrossilvicultural, submetidas a extremos climáticos de geada na região de Florianópolis. Revista Árvore, v.27, n.5, p.627-634, 2003. 